\title{
REVIEWS
}

Adv Clin Exp Med 2015, 24, 6, 1105-1112

(C) Copyright by Wroclaw Medical University

DOI: $10.17219 /$ acem $/ 43834$

ISSN 1899-5276 Kamil Kaczorowski $^{\text {B-D }}$, MaŁgorzata Mulak
Marta Misiuk-HojŁo $^{\text {F }}$

\section{Heidelberg Edge Perimeter: The New Method of Perimetry}

Department and Clinic of Ophthalmology, Wroclaw Medical University, Poland

A - research concept and design; $\mathbf{B}$ - collection and/or assembly of data; $\mathbf{C}$ - data analysis and interpretation;

$\mathbf{D}$ - writing the article; $\mathbf{E}$ - critical revision of the article; $\mathbf{F}$ - final approval of article

\begin{abstract}
Glaucoma is an optic nerve neuropathy associated with progressive visual field loss. One of the most frequent eye diseases these days, it is believed to have affected 60 million people worldwide in 2014. Various visual field examination methods are known, from the confrontational test to kinetic and static perimetry. The latest device to access the visual field is the Heidelberg Edge Perimeter (HEP). It is a flicker perimeter, but, unlike others of its kind, it uses a unique stimulus called FDF (Flicker Defined Form). A 5-grade round stimulus is created by reversing the phase of flickering black and white dots, thereby forming illusory outlines. The test uses randomly flickering points in medium illumination $\left(50 \mathrm{~cd} / \mathrm{m}^{2}\right)$. The background remains the same during the whole test. Background luminance is $50 \mathrm{~cd} / \mathrm{m}^{2}$, the marker showing time is $400 \mathrm{~ms}$, and the frequency is $15 \mathrm{~Hz}$. Current studies show that HEP can detect early visual field loss which remains invisible during a standard visual field test with standard automated perimetry. HEP might also prove useful in the early detection of other diseases connected with visual field loss, for example in neurology (Adv Clin Exp Med 2015, 24, 6, 1105-1112).
\end{abstract}

Key words: glaucoma, visual field, Heidelberg Edge Perimeter (HEP), flicker defined form.

Glaucoma is an optic nerve neuropathy associated with progressive visual field loss. One of the most frequent eye diseases these days, it is believed to have affected $60 \mathrm{~m}$ people worldwide in 2014 [1]. It has also been estimated that over $20 \mathrm{~m}$ patients will have lost their sight due to glaucoma by 2020 [2].

Nowadays it is said that glaucoma damage doesn't only affect optic nerve fibers, but also retinal ganglion cells [RGC] [3], which become damaged at an even earlier stage [4]. The type and timing of cellular changes leading to RGC loss in glaucoma remain incompletely understood, including whether specific RGC subtypes are preferentially impacted at early stages of the disease [5]. It seems that magnocellular retinal cells (M-cells) are more sensitive than parvocellular retinal cells (P-cells) and become some of the first to be damaged in glaucoma [6]. Since these cells are very sensitive to glaucoma damage, they suffer complete loss at an early stage of glaucoma [7], which in turn influences the visual function and thus the visual field as well. Therefore, early detection of these defects is crucial to starting the treatment in time. It has been noted that substantial retinal ganglion cell damage can happen long before its detection using standard examinations assessing RGC damage [8]. Some authors, however, claim that $\mathrm{M}$-cell damage does not affect the results of visual field examinations [9].

Due to its mostly symptomless beginnings, glaucoma is hard to diagnose. That is why preventive treatment and performing periodic health tests are crucial. The most important examination assessing optic nerve function is a visual field test.

\section{Visual Field}

Visual field is a term for the area one sees while the eye is still. Another, more intuitive definition would be 'the vision island' surrounded by the 'sea of darkness' [10]. Measurements of the visual field 
can be taken with a perimeter. The visual field was first measured by Thomas Young, then, in 1825, Purkinje modified Young's ranges, changing them to $60^{\circ}$ nasal, $100^{\circ}$ temporal, $60^{\circ}$ in the upper and $80^{\circ}$ in the lower field [10]. It was Albrecht von Gräfe that first introduced perimetry into clinical practice [11].

In the course of glaucoma development, the visual field decreases in a characteristic way, related to the arrangement of nerve fibers in the retina and the way they come from its specific parts. The fibers from the spot and the nasal part of the retina go immediately to the optic nerve disc, whilst those from the retina's temporal segment make bends. The latter are also the most sensitive to glaucomatous damage. Visual field tests in glaucomatous patients prove the existence of bends in which no visual information is perceived [12].

\section{Visual Field Test}

Various visual field examination methods are known, from the confrontational test to kinetic and static perimetry.

Kinetic perimetry is the oldest measurement technique known. It consists of showing the patient a marker whose illumination is changing. The clinician moves the marker at a speed varying from $2 \%$ to $5 \%$ from the area in which the patient cannot see it to where it becomes noticeable [13]. The patient informs the doctor when they can see the marker, owing to which isopters (lines connecting the visibility areas of a marker given) are obtained.

Currently, the most common visual field examination method is static perimetry. It presents many markers of changing illumination in the same area in such a way that the smallest degree of marker brightness in that place can be determined [14]. This way a three-dimensional vision island of the patient is established, using which one can state where exactly the patient's response to light stimuli is weaker than it should be based on the patient's age. Following the invention of automatic perimeters, this technique has become much easier and faster than kinetic perimetry.

Markers may vary in size and illumination as well as showing time. Their size is normally given using the 5-grade Goldmann scale, whose markers are $1 / 16$ to $64 \mathrm{~mm}^{2}$ big. The marker's showing time varies according to the device. The illumination, measured in apostilbs or decibels in perimetry, is an indication of stimulus intensity.

Static perimeters measure the patient's response in the central and peripheral visual fields, whose width is usually $10^{\circ}, 24^{\circ}, 30^{\circ}$ and $60^{\circ}$. Tests are marked as, for example, 24-2 or 30-1, with the first digit indicating the range of the visual field test (given in degrees) and the latter (either 1 or 2) - the marker arrangement [15].

The most frequent Standard Automated Perimeters (SAP) are Humphrey and Octopus, recommended by the European Glaucoma Society as the most useful for routine glaucoma diagnostics [16]. The basic element of a perimeter is a hemisphere-shaped cap, within which markers are shown at any place given. A change in marker intensity can be achieved through an alteration in its size or illumination.

Another perimeter type is Flicker Defined Perimetry (whose one example is the Heidelberg Edge Perimeter - HEP), which uses static perimeters using a different kind of stimulation - a flickering marker of periodically changing illumination $[17,18]$. It is more difficult to detect, which is believed to be related to the lesser sensitivity of magnocellular retinal cells $[18,19]$. These perimeters are particularly useful in detecting early glaucomatous changes.

The frequency-doubling technology (FDT) perimeter is similar to Flicker Defined Perimetry in terms of usage. The eye observes a sinusoidal net of a low spatial frequency, but flickering with a high frequency and perceives it as an element of twice as big spatial frequency, which is an optical illusion $[15,20]$. As in flicker perimetry, M-cells do react to this kind of stimulus, which provides information about the early stage of glaucoma [21].

\section{Heidelberg Edge Perimeter}

HEP is a flicker perimeter, but, unlike others of this kind, it uses a unique stimulus called Flicker Defined Form (FDF). A 5-grade round stimulus is created by reversing the phase of flickering black and white dots, thereby forming illusory outlines $[22,23]$. The test uses randomly flickering points in medium illumination $\left(50 \mathrm{~cd} / \mathrm{m}^{2}\right)$. The background remains the same during the whole test. Background luminance is $50 \mathrm{~cd} / \mathrm{m}^{2}$, with a marker showing time of $400 \mathrm{~ms}$, whereas the frequency is $15 \mathrm{~Hz}$.

HEP can be used for testing peripheral as well as central visual field, $10^{\circ}, 24^{\circ}, 30^{\circ}$ or $60^{\circ}$ wide. An SAP examination can also be performed the same way as on a standard perimeter.

HEP operates two different stimuli: round FDF, which can be $3^{\circ}$ wide for the 10-3 test and $5^{\circ}$ for the 24-2, 30-2 and S-30 as well as SAP - II on the Goldmann scale for 10-2, 24-2 and 30-2 as well as $\mathrm{V}$ for $10-2,24-2$ and $30-2$. 
The following examinations can be carried out using the HEP field analyzer: S-30 (FDF), 10-3 (FDF), 10-2 (SAP III), 24-2 (FDF), 24-2 (SAP III and V), 30-2 (FDF) and 30-2 (SAP III).

Also, the HEP perimeter uses different test strategies: Adaptive Staircase Thresholding Algorithm (ASTA) was elaborated by prof. John Flanagan. His technique uses the step function up or down, modifying it to suit the database. The results are presented as a sensitivity measure expressed in decibels $(\mathrm{dB})$. Three ASTA strategies are operated by HEP: Standard, Follow-up and Fast.

ASTA Standard is based on a probability estimate in order to ensure optimum test effectiveness. This strategy ought to be performed on all new patients as it provides satisfying results and enables the assessment of possible defect progression. First the $4: 2: 2$ strategy is used to determine loss in a segment given, then, if the patient cannot see the stimulus, the power is increased first by $4 \mathrm{~dB}$, which makes the stimulus more noticeable, and by an additional $2 \mathrm{~dB}$ should the stimulus still not be seen. This sensitivity is a starting point for the neighboring areas, where the strategy used is $2: 2$. Should these segments differ a lot from the rest or be very limited, they ought to be tested again.

ASTA Follow-up is a test that can be performed following the others. It compares the results of previous examinations with the current ones; this strategy uses the $2: 2$ step function and is faster than ASTA Standard.

The ASTA Fast algorithm uses the $4: 2$ function, thereby making the examination faster. It is recommended for the monitoring of 'within the normal range' patients or those who have previously proven tired of the examination methods. The results are less comparable, but the test is shorter.

HEP also has different screening test strategies at its disposal. Since the examination time is shorter, it is particularly advisable in the case of patients who cannot take a long test.

Reliability measures such as fixation losses (FL), false positive errors (FP) or false negative errors (FN) are taken into account while interpreting the test results [15]. Fixation losses imply the patient having wrongly looked sideways, while false positive errors indicate the patient has pressed the 'stimulus' button automatically, without having really seen it. False negative errors take place when the patient doesn't notice a marker of greater brightness than that seen in the same location before. The results of the test can be analyzed from a graphical printout.

Heidelberg Retina Tomograph (HRT) can be connected to the HEP so that examinations from both can be compared and analyzed by a special program. HRT is a device used for measuring optic nerve fiber thickness right by the edge of the optic disc. The measurement once taken is then compared to the apparatus' database, which contains the range of 'normal' results for each patient age. The possibility of connecting HEP and HRT makes it possible to assess existing visual field loss.

\section{HEP Examinations so Far}

HEP is a new perimeter whose advantages and drawbacks are being intensely examined all over the world. It has only been used for patient examination for a few years now, therefore, rather few works on its effectiveness in visual field testing are known so far.

The introduction of a new perimeter has made it necessary to compare it to those already in use. As a logarithmic scale measuring the sensitivity to a stimulus, a decibel range is used for evaluating glaucoma defect. 'Zero' on the decibel scale equals a complete lack of reaction to the brightest stimulus. The greater the decibel value, the darker the stimuli that were noticed. The decibel scale, however, is not the same for different parameters. ' 0 ' on the Octopus device doesn't denote the same as ' 0 ' for Humphrey [24]. The comparison has been shown in Table 1.

The range of the HEP scale is $0-25 \mathrm{~dB}$ and it is not easily compared to the Humphrey results. Nevertheless, the device itself has a program which converts its measurements to the generally recognized SAP perimeter scale - HEP software release

Table 1. The comparison of decibel scales in SAP (Humphrey) and FDF (HEP)

\begin{tabular}{|l|l|l|}
\hline & SAP & FDF \\
\hline Size of the stimulus & Goldman III and V & $5 \times 5^{\circ}$ for $24^{\circ}, 30^{\circ}$ and $60^{\circ}$ visual field, $3 \times 3^{\circ}$ for $10^{\circ}$ \\
\hline Luminance of the stimulus & $40-0 \mathrm{~dB}$ & $28-0 \mathrm{~dB}$ \\
\hline Brightness of the background & $10 \mathrm{~cd} / \mathrm{m}^{2}$ & $50 \mathrm{~cd} / \mathrm{m}^{2}$ \\
\hline Test conditions & test carried out in a dark room & test carried out in normal light \\
\hline
\end{tabular}


Heidelberg Edge Perimeter

HEP Single Field Report (General)

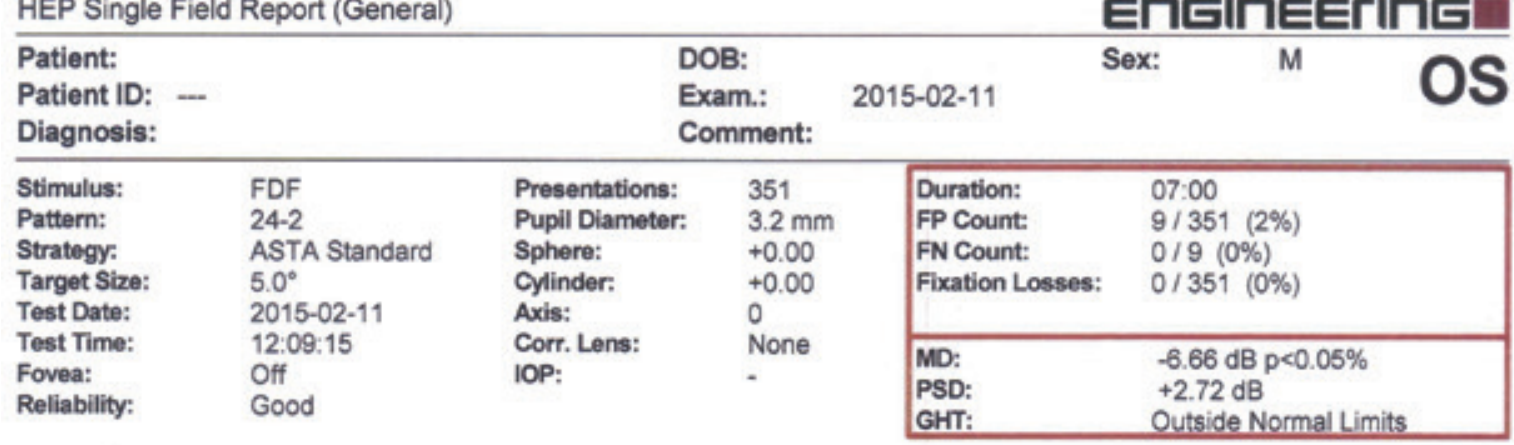

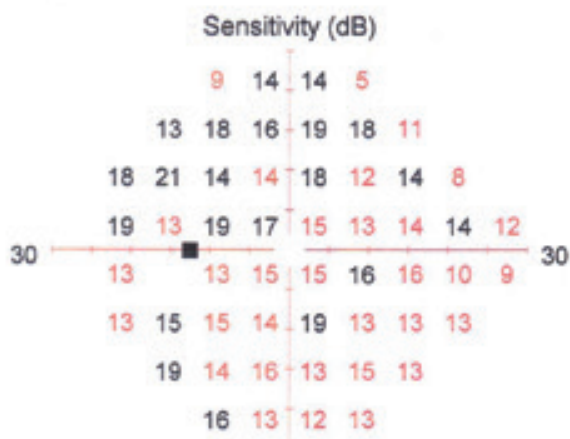

Total Deviation

$\begin{array}{llll}-9 & -4 & -5 & -13\end{array}$

$\begin{array}{llllll}-7 & -2 & -5 & -2 & -3 & -9\end{array}$

$\begin{array}{llllllll}-2 & 0 & -7 & -7 & -4 & -9 & -7 & -11\end{array}$

$\begin{array}{llllllll}-2 & -3 & -5 & -7 & -9 & -8 & -6 & -7 \\ -8 & -9 & -8 & -7 & -6 & -6 & -10 & -10\end{array}$

$\begin{array}{llllllll}-8 & -7 & -8 & -9 & -3 & -9 & -9 & -7\end{array}$

$\begin{array}{llllll}-3 & -8 & -7 & -9 & -7 & -8\end{array}$

$\begin{array}{llll}-5 & -8 & -8 & -7\end{array}$

Total Deviation

$0-00$

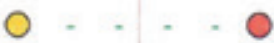

$00-000$

$-000000$

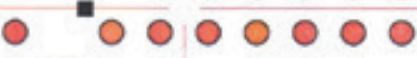

- $000-000$

00000

0000

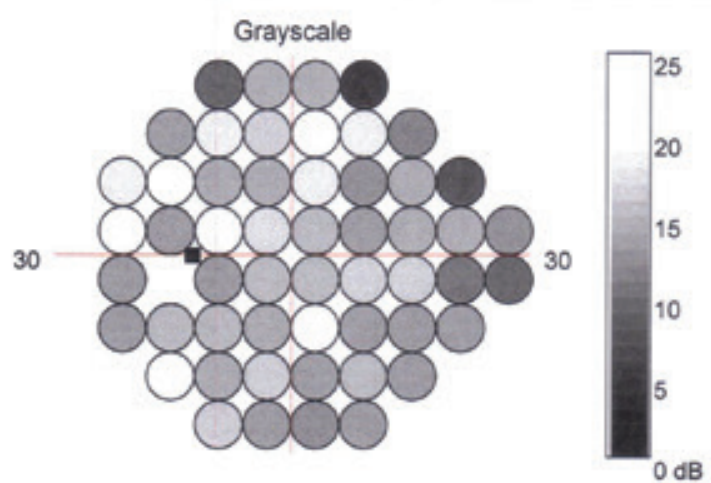

Pattern Deviation

$\begin{array}{llll}-6 & -1 & -2 & -10\end{array}$

$\begin{array}{llllll}-4 & 1 & -2 & 1 & 0 & -6\end{array}$

$\begin{array}{llllllll}1 & 3 & -4 & -4 & -1 & -6 & -4 & -8\end{array}$

$\begin{array}{llllllll}1 & 0 \\ -6 & -6 & -5 & -4 & -3 & -3 & -7 & -7\end{array}$

$\begin{array}{llllllll}-6 & -4 & -5 & -6 & 0 & -6 & -6 & -4\end{array}$

$\begin{array}{llllll}0 & -5 & -4 & -6 & -4 & -5\end{array}$

$\begin{array}{llll}-2 & -5 & -5 & -4\end{array}$

$\bigcirc p<5$

Pattern Deviation

p $<2$

○- 0 P 0 <1
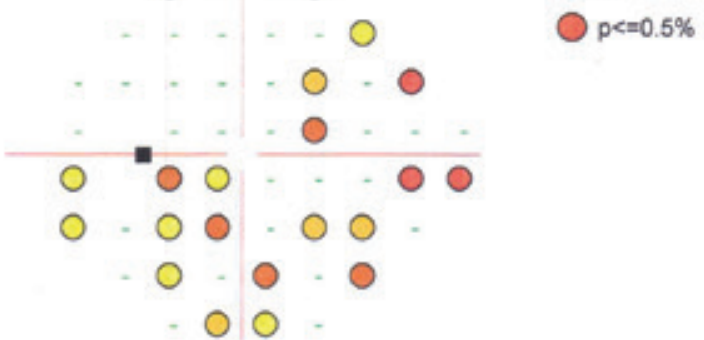

Reliability Parameters

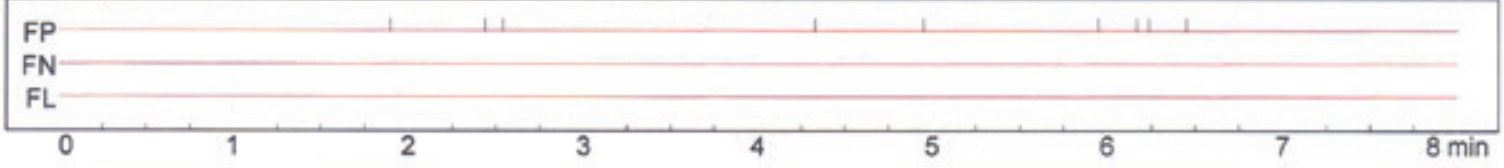

Notes:

Fig. 1. Printout from the HEP (authors' own material) 


\begin{tabular}{|c|c|}
\hline Single Field Analysis & Eye: Left \\
\hline Name: & DOB: \\
\hline
\end{tabular}

Central 24-2 Threshold Test

Fixation Monitor: Gaze/Blind Spot

Fixation Target: Central

Fixation Losses: 0/10

False POS Errors: $5 \%$

False NEG Errors: $0 \%$

Test Duration: 03:05

Fovea: OFF

$\begin{array}{lll}\text { Stimulus: III, White } & \text { Pupil Diameter: } & \text { Date: } 11-02-2015 \\ \text { Background: } 31.5 \text { ASB } & \text { Visual Acuity: } & \text { Time: } 10: 02 \\ \text { Strategy: SITA-Fast } & \text { RX: DS DC X } & \text { Age: } 31\end{array}$

Background: 31.5 ASB

Strategy: SITA-Fast
Pupil Diameter:
Visual Acuity:
RX: DS DC X

Age: 31

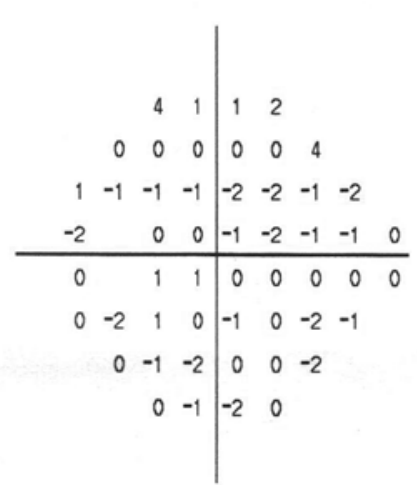

Total Deviation

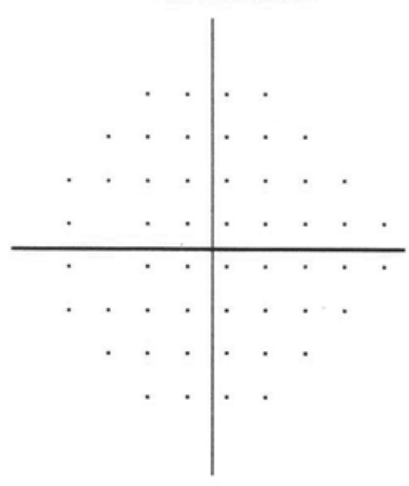

30 \begin{tabular}{llll|lllll}
29 & 30 & 33 & 34 & 33 & 31 & 32 & 31 & 30 \\
\hline 32 & $<<0$ & 34 & 35 & 34 & 33 & 33 & 31 & 30
\end{tabular}

\begin{tabular}{llll|llll}
32 & 31 & 34 & 33 & 32 & 34 & 31 & 30
\end{tabular}

$\begin{array}{llllll}32 & 31 & 30 & 32 & 32 & 29\end{array}$

$31 \quad 30-29 \quad 31$

$::<5 \%$

\%) $<2 \%$

粦 $<1 \%$

- $<0.5 \%$

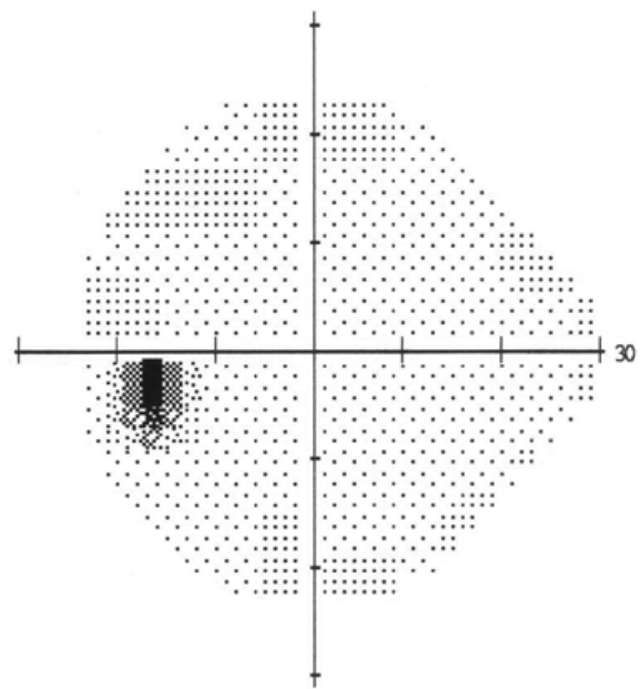

$\begin{array}{llll}3 & 1 & 1 & 2\end{array}$

$\begin{array}{lllllll}-1 & -1 & -1 & -1 & 0 & 3\end{array}$

\begin{tabular}{llll|llll}
0 & -1 & -2 & -1 & -3 & -2 & -1 & -2
\end{tabular} \begin{tabular}{cccccccc}
-3 & -1 & 0 & -1 & -3 & -1 & -1 & 0 \\
\hline 0 & 0 & 0 & -1 & -1 & -1 & -1 & 0
\end{tabular}

\begin{tabular}{llll|llll}
0 & -2 & 0 & -1 & -2 & 0 & -2 & -2
\end{tabular}

\begin{tabular}{lll|llll}
-1 & -2 & -3 & -1 & -1 & -2
\end{tabular}

$\begin{array}{llll}-1 & -2 & -2 & 0\end{array}$

Pattern Deviation

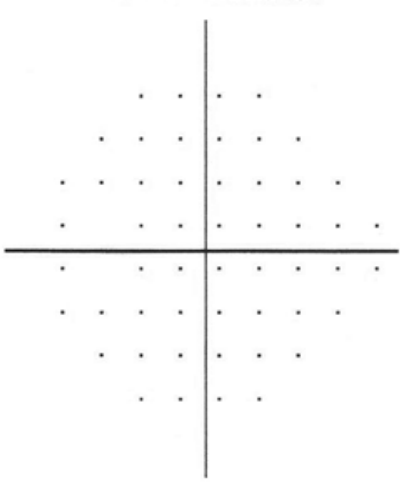

KLINIKA OKULISTYCZNA

AM WE WROCLAW

UL. BOROWSKA 213

55-556 WROCLAW
GHT

Within Normal Limits

VFI $100 \%$

MD $\quad-0.40 \mathrm{~dB}$

PSD $\quad 1.21 \mathrm{~dB}$

Fig. 2. Printout from the SAP (Humphrey) (authors' own material) 
2.2 which includes: HEP Acquisition Module $(A Q M)$ v. 2.2, HEP Viewing Module (VWM) v. 2.2 and Heidelberg Eye Explorer (HEYEX) v. 1.7. Owing to that, a comparison of the results obtained is possible. Differences in the decibel values are crucial to assessing the stage of glaucoma defect. Thus far the Hodapp differentiation method has been used to indicate it in SAP perimeters: 0-6 dB means small glaucoma damage, $6-12 \mathrm{~dB}$ indicates medium changes, whereas above $12 \mathrm{~dB}$ means serious damage [26]. It hasn't been stated whether the same criteria can be applied to HEP yet.

The differences between HEP and standard perimeters are only now being established. Some of the first studies have already demonstrated the HEP visual field test can detect changes at an earlier stage than standard perimetry. In 2012, Hasler S. and Stürmer J. claimed that the Heidelberg Edge perimetry seemed to be more sensitive than conventional static perimetry in the early detection of visual field alterations in patients with ocular hypertension and incipient glaucoma [27].

Despite normal visual field findings in the Octopus perimetry $(\mathrm{MD}<2.0 \mathrm{~dB})$, pathological visual fields have been detected in 48 out of 90 eyes with the HEP examination (53\%).

Examinations with flicker defined form (FDF) and frequency doubling technology (FDT) perimetry have been carried out to determine their ability to detect glaucoma at an earlier stage than standard automated perimetry (SAP) [27]. The purpose of the study was to examine the structure-function relationship between FDF, FDT, SAP, and confocal scanning laser ophthalmoscopy (cSLO) in glaucoma patients. FDF perimetry presented with the strongest structure-function relationship (global correlation with the rim area was 0.44 , whereas the range of significant sectoral FDF values was 0.23 -0.69), followed by FDT (whose global correlation with the rim area was 0.35 and the range of significant sectoral FDT values: $0.25-0.60)$. SAP featured the weakest structure-function relationship and fewer statistically relevant results (global correlation: 0.32 ; the range of significant sectoral SAP values: $0.23-0.58)$. The correlation between structure and function was stronger for FDF and FDT than in SAP. The connections appeared strongest in temporal areas - usually the first to suffer glaucomatous damage.

While examining patients who were clinically suspicious for glaucoma due to optic nerve head $(\mathrm{ONH})$ or retinal nerve fiber layer (RNFL) damage, it was noted that in more than half of them FDF managed to detect visual field loss while SAP still gave 'normal' results [23]. The comparison of HEP and SAP results in patients with primary open-angle glaucoma proved that out of the total of 42 open angle glaucoma (OAG) patients with abnormal SAP MD, 38 also had pathological FDF MD (mean deviation). Nevertheless, FDF MD was aberrant in 28 out of $55 \mathrm{OAG}$ patients with normal SAP MD. The FDF MD proved more correlated with RNFL thickness than SAP MD. To conclude, FDF perimetry may be useful in early glaucomatous nerve atrophy detection [21].

Performing HEP is particularly important in the case of glaucoma suspicion. Horn et al. have pointed out that the FDF stimulus is able to detect early glaucoma damage [22]. Patients with SAP $\mathrm{MD}$ values exceeding $5 \mathrm{~dB}$ should be monitored with conventional perimetry because of its larger dynamic range.

The usefulness of HEP in early glaucoma detection has also been emphasized by other authors. Prokosch et al. [28] have compared whiteon-white standard automated perimetry (SAP), matrix frequency doubling technology (FDT), and flicker-defined form perimetry (FDF) in their use for detecting nerve fiber layer loss in patients at an early stage of glaucoma. They concluded that the sensitivity to RNFL loss detection in early glaucoma appeared higher in FDF and FDT matrix than in SAP perimetry, much as the specificity was highest in SAP. The sensitivity was highest for FDF perimetry $(87 \%)$, followed by FDT matrix $(62.5 \%)$ and then SAP (40\%). MD and pattern standard deviation (PSD) in FDF and FDT matrix were significantly different between patients with RNFL loss and those without it $(\mathrm{p}<0.05)$, while no difference had been found in SAP. That is why simultaneous use of FDF/FDT matrix and SAP perimetry is recommended for fully accurate results.

Studies aiming to improve the understanding of perimeter work mechanisms are also being carried out. Shahidi et al. have pointed out the differences in HEP-FDF and FDT matrix stimuli, based on the findings from their own study: the visual sensitivity increase noted was only significant for HEP-FDF stimuli and not for the other device examined [29].

Clinicians' current experience proves the patient should undergo the examination a few times in order for the visual field to be evaluated properly. It is key to let the eyes rest in-between tests, as it will enable more accurate measurements. The HEP test is more difficult and tiring for patients, as the marker is harder to notice [30]. Therefore, this examination type requires younger patients, easy to collaborate with and without additional eye diseases which could have an impact on visual acuity (e.g. cataract). In most patients, this test takes more time than that performed on Humphrey or 
Octopus. As in the case of other perimeters, the patient has to learn to undergo this examination. Usually, the first two or three results are not as reliable as the later ones, which has to do with the marker notice learning effect, correct eye position and general examination learning.

Another relevant issue is contrast sensitivity in the patient, which may heavily influence the results. In the case of reduced contrast sensitivity, patients examined using the HEP perimeter can experience trouble seeing the stimulus, which is dark grey and shown against a flickering grey background.

\section{Conclusions}

The crucial element of glaucoma treatment is an early diagnosis, when only few nerve fibers have been damaged and the patient can undergo treatment for many years to come, using the slowdown methods available and continuing to have good visual field. Current studies show that the HEP can detect early visual field loss which remains invisible during a standard visual field test with the SAP perimeter. HEP might also prove useful in the early detection of other diseases connected with visual field loss, for example in neurology.

\section{References}

[1] Weinreb R: Glaucoma Worldwide: A Growing Concern (February 2015). Available from: http://www.glaucoma. org/gleams/glaucoma-worldwide-a-growing-concern.php.

[2] Facts about Glaucoma, National Eye Institute (February 2015). Available from: http://www.nei.nih.gov/health/ glaucoma/glaucoma_facts.asp.

[3] Chen YS, Green CR, Danesh-Meyer HV, Rupenthal ID: Neuroprotection in the treatment of glaucoma - A focus on connexin43 gap junction channel blockers. Eur J Pharm Biopharm 2015.

[4] Park JW, Jung HH, Heo H, Park SW: Validity of the temporal-to-nasal macular ganglion cell-inner plexiform layer thickness ratio as a diagnostic parameter in early glaucoma. Acta Ophthalmol 2015.

[5] El-Danaf RN, Huberman AD: Characteristic patterns of dendritic remodeling in early-stage glaucoma: evidence from genetically identified retinal ganglion cell types. J Neurosc 2015, 35, 2329-2343.

[6] Kerrigan-Baumrind LA, Quigley HA, Pease ME, Kerrigan DF, Mitchell RS: Number of ganglion cells in glaucoma eyes compared with threshold visual field tests in the same persons. Invest Ophthalmol Vis Sci 2000, 41, 741-748.

[7] Maddess T, Hemmi JM, James AC: Evidence for spatial aliasing effects in the Y-like cells of the magnocellular visual pathway. Vision Res 1998, 38, 1843-1859.

[8] Hood DC, Kardon RH: A framework for comparing structural and functional measures of glaucomatous damage. Prog Ret Eye Res 2007, 26, 688-710.

[9] White AJ, Sun H, Swanson WH, Lee BB: An examination of physiological mechanisms underlying the frequencydoubling illusion. Invest Ophthalmol Vis Sci 2002, 43, 3590-3599.

[10] Simpson DA, Crompton JL: The Visual Fields: An Interdisciplinary History II. Neurosurgeons and Quantitative Perimetry. J Clin Neurosc 2008, 15, 229-236.

[11] Lanska DJ, von Gräfe A: In: Aminoff MJ, Daroff RB, editors. Encyclopedia of the Neurological Sciences (Second Edition). Oxford: Academic Press 2014, 475-476.

[12] Fankhauser F, Spahr J, Bebie H: Some aspects of the automation of perimetry. Survey of Ophthalmology 1977, 22, 131-141.

[13] Mills R: Perimetry With and Without Automation. Am J Ophthalmol 1987, 104, 197.

[14] Schiefer U, Patzold J, Wabbels B, Dannheim F: Conventional techniques of visual field examination: part 4 Static perimetry: interpretation - perimetric indices - follow-up - perimetry in childhood. Ophthalmologe 2006, 103, 235-254.

[15] Henson DB: Perimetry. In: Dartt DA, editor. Encyclopedia of the Eye. Oxford: Academic Press 2010, 300-306.

[16] Hitchings R: Terminology and Guidelines for Glaucoma (February 2015). Available from: http://www.eugs.org/ eng/EGS_guidelines.asp.

[17] Dannheim F: Flicker and conventional perimetry in comparison with structural changes in glaucoma. Ophthalmologe 2013, 110, 131-140.

[18] Yoshiyama KK, Johnson CA: Which method of flicker perimetry is most effective for detection of glaucomatous visual field loss? Invest Ophthalmol Vis Sci 1997, 38, 2270-2277.

[19] Comer GW: Chapter 15 - Visual-Field Screening and Analysis. In: BenjaminConsultant WJ, Borish IM, editors. Borish's Clinical Refraction (Second Edition). Saint Louis: Butterworth-Heinemann 2006, 544-618.

[20] Kelly DH: Frequency Doubling in Visual Responses. J Opt Soc Am 1966, 56, 1628-1632.

[21] Horn FK, Tornow RP, Junemann AG, Laemmer R, Kremers J: Perimetric measurements with flicker-defined form stimulation in comparison with conventional perimetry and retinal nerve fiber measurements. Invest Ophthalmol Vis Sci 2014, 55, 2317.

[22] Horn FK, Kremers J, Mardin CY, Junemann AG, Adler W, Tornow RP: Flicker-defined form perimetry in glaucoma patients. Graefe's Arch Clin Exp Ophthalmol 2014.

[23] Reznicek L, Lamparter J, Vogel M, Kampik A, Hirneiss C: Flicker Defined Form Perimetry in Glaucoma Suspects with Normal Achromatic Visual Fields. Cur Eye Res 2014, 1-7. 
[24] Sharma P, Sample PA, Zangwill LM, Schuman JS: Diagnostic Tools for Glaucoma Detection and Management. Surv Ophthalmol 2008, 53, Suppl 6, 17-32.

[25] Mills RP, Hopp RH, Drance SM: Comparison of Quantitative Testing with the Octopus, Humphrey, and Tübingen Perimeters. Am J Ophthalmol 1986, 102, 496-504.

[26] Susanna R Jr, Vessani RM: Staging Glaucoma Patient: Why and How? Open Ophthalmol J 2009, 3, 59-64.

[27] Hasler S, Stürmer J: First experience with the Heidelberg Edge Perimeter ${ }^{\circledR}$ on patients with ocular hypertension and preperimetric glaucoma. Klin Monbl Augenheilkd 2012, 229, 319-322. DOI: 10.1055/s-0031-1299210. Epub 2012 Apr 11.

[28] Prokosch V, Eter N: Correlation between early retinal nerve fiber layer loss and visual field loss determined by three different perimetric strategies: white-on-white, frequency-doubling, or flicker-defined form perimetry. Graefe's Arch Clin Exp Ophthalmol 2014, 252, 1599-1606.

[29] Shahidi AM, Hudson C, Patel SR, Flanagan JG: The effect of hypercapnia on the sensitivity to flicker defined stimuli. Br J Ophthalmol 2015, 99, 323-328.

[30] Mulak M, Szumny D, Sieja-Bujewska A, Kubrak M: Heidelberg edge perimeter employment in glaucoma diagnosis - preliminary report. Adv Clin Exp Med 2012, 21, 665-670.

\section{Address for correspondence:}

Kamil Kaczorowski

Department and Clinic of Ophthalmology

Wroclaw Medical University

Borowska 213

50-556 Wrocław

Poland

Tel: +48534834355

E-mail: drkamilkaczorowski@gmail.com

Conflict of interest: None declared

Received: 4.03.2015

Revised: 12.05 .2015

Accepted: 26.05.2015 